\title{
Adenosarcoma pT1a TNM Finding v7
}

National Cancer Institute

\section{Source}

National Cancer Institute. Adenosarcoma pT1a TNM Finding v7. NCI Thesaurus. Code C89612.

Tumor limited to endometrium/endocervix. (from AJCC 7th Ed.) 